\title{
Seven-year time trends in energy balance-related behaviours according to educational level and ethnic background among 14-year-old adolescents
}

\author{
Frederika J Meijerink ${ }^{1,2}$, C Leontine van Vuuren ${ }^{1, *}$, Hanneke AH Wijnhoven ${ }^{2}$ and \\ Manon van Eijsden ${ }^{1}$ \\ 'Department of Epidemiology and Health Promotion, Public Health Service (GGD) Amsterdam, PO Box 2200, 1000 \\ CE Amsterdam, The Netherlands: ${ }^{2}$ Department of Health Sciences and the EMGO + Institute for Health and Care \\ Research, Faculty of Earth and Life Sciences, VU University Amsterdam, Amsterdam, The Netherlands
}

Submitted 18 July 2014: Final revision received 20 March 2015: Accepted 15 April 2015: First published online 19 June 2015

\begin{abstract}
Objective: To assess seven-year time trends in energy balance-related behaviours in 14-year-old adolescents living in an urban area and to examine the influence of educational level and ethnicity on these time trends.

Design: Second grade students (mean age 13.6 years) filled in questionnaires about the energy balance-related behaviours of breakfast consumption, fruit and vegetable consumption, physical activity and screen-time behaviour from school years 2006-2007 to 2012-2013. Energy balance-related behaviours were dichotomized and logistic regression analyses were used to examine time trends in healthy energy balance-related behaviours, including interaction terms for educational level and ethnicity.

Setting: Secondary schools in Amsterdam, the Netherlands.

Subjects: Per school year, 2185-3331 children participated. The total sample included 19244 students of Dutch, Surinamese, Turkish and Moroccan ethnic background.

Results: A significant linear increase was found for positive screen-time behaviour $(<2 \mathrm{~h} / \mathrm{d}$; OR per year $=1.04 ; 95 \%$ CI $1.03,1.06)$. For daily vegetable consumption a non-linear negative trend was observed (school year 2012-2013 v. 2006-2007: $\mathrm{OR}=0.90 ; 95 \% \mathrm{CI} 0.80,1.00)$. Time trends in screen time were significantly different across educational levels $(P$-interaction $=0 \cdot 002)$ and ethnic backgrounds $(P<0.001)$, as were time trends in daily fruit consumption $(P=0.017$ and $P=0 \cdot 018$, respectively) and, for ethnicity, trends in daily vegetable consumption $(P<0.001)$.

Conclusions: The increase in positive screen-time behaviour is a positive finding. However, discouraging screen time and promoting other healthy behaviours, more specifically daily fruit and vegetable consumption, remain important particularly among adolescents enrolled in pre-vocational education and of nonDutch ethnic background.
\end{abstract}

Keywords
Time trends
Energy balance-related behaviours
Adolescents
Education
Ethnicity
Over the past 30 years, there has been a dramatic increase in overweight among children and adolescents in developed countries ${ }^{(1)}$. However, more recent studies suggest that prevalence rates in overweight have stabilized since the late $1990 \mathrm{~s}^{(2,3)}$. In the Netherlands, a stabilizing trend has been observed, but only in the four largest cities (Amsterdam, The Hague, Rotterdam and Utrecht) ${ }^{(4,5)}$. Overweight prevalence rates among children and adolescents living in these cities were stable at 14\% between 1997 and 2009, whereas in other regions the prevalence rose from $9 \%$ to almost $13 \%^{(4)}$. A recent study in The Hague, examining time trends among four ethnic groups (Dutch, Turkish, Moroccan and Surinamese South Asian), even showed a significant decrease in overweight prevalence between 1999 (13\%) and 2011 (11\%), but only for the children and adolescents of Dutch ethnic background ${ }^{(5)}$.

In the past few years, overweight prevention strategies have been targeted specifically towards the population in the urban areas in the Netherlands, and the observed stabilizing and decreasing trends in overweight might 
indicate that children and their parents have become more aware of important energy balance-related behaviours (EBRB). EBRB are behaviours that presumably determine energy intake and energy expenditure and are thereby factors that contribute to overweight when intake exceeds expenditure $^{(6)}$. Examples of healthy EBRB are, among others, regular breakfast consumption, daily fruit and vegetable consumption, regular physical activity (e.g. participation in sports and walking or cycling to school) and limited screen time (watching television (TV) or playing sedentary computer games) ${ }^{(7-11)}$. Targeting these EBRB in health-promotion strategies becomes even more important as children grow older, because they will become more and more autonomous in their behavioural choices ${ }^{(12)}$.

Previous studies have shown that adolescents with low socio-economic status/education and adolescents of nonDutch ethnic background are more likely to skip breakfast $^{(13-15)}$, to be less physically active ${ }^{(16,17)}$, to watch more TV and to play more sedentary computer games ${ }^{(18,19)}$. At the same time, they are at higher risk of developing overweight than adolescents of Dutch ethnic background $^{(20,21)}$. Although we expect general positive trends in EBRB based on the stabilizing or decreasing time trend of overweight in Dutch urban cities, this could coincide with negative trends in lower educated adolescents and adolescents of non-Dutch ethnic background. To adequately target health-promotion activities for adolescents, insight into the time trends of important EBRB, and ethnic and educational disparities therein, is essential. The present study therefore aimed to: (i) investigate seven-year time trends in EBRB among 14-year-old Dutch adolescents in the city of Amsterdam; and (ii) examine the influence of educational level and ethnicity on these time trends.

\section{Methods}

\section{Sample and materials}

Data for the present study were available from the Youth Health Monitor used by the Public Health Service Amsterdam. The Youth Health Monitor is an annually ongoing project to assess the health status of adolescents in secondary schools in Amsterdam. Results of the monitor are used to develop health policies and health-promoting activities targeted at adolescents. From school year 20062007 to school year 2009-2010, data were collected on demographics and different lifestyle factors of 13- to 14year-old second grade students by a paper questionnaire. From school year 2010-2011 to school year 2012-2013 an electronic questionnaire was used. Questions in the Youth Health Monitor are used nationally and based on international, validated questionnaires where possible. Every year, all regular secondary schools in Amsterdam are approached by the Public Health Service Amsterdam to participate in the project. Each year before data collection, information letters are sent to parents and students.
A passive informed consent procedure is used, thus students and their parents can decide to not take part in the Youth Health Monitor. Questionnaires are completed confidentially in class, under the supervision of teachers and employees of the Public Health Service Amsterdam. Annual response rates of participating schools in Amsterdam are over $90 \%$. Approximately 37000 adolescents completed the questionnaires between school year 20062007 and school year 2012-2013. The project is registered at the Dutch Data Protection Authority.

\section{Measures}

In the paper and electronic questionnaires adolescents were asked about numerous health topics. Questions were, among others, related to sociodemographic factors, health, drugs, alcohol, smoking, sexuality, nutrition and physical activity (including screen-time behaviour). In the present study, only questions related to sociodemographic variables, nutrition and physical activity were used.

\section{Breakfast consumption}

To assess breakfast consumption the following question was used: 'How many days per week do you eat breakfast?', with response values ranging from 0 to $7 \mathrm{~d} /$ week $^{(22)}$. To calculate the percentage of adolescents with healthy breakfast behaviour, a dichotomous variable was made with 'non-regular' (0-4 d/week) and 'regular' (5-7 d/week) as values. The cut-off point was based on a previous crosssectional study that showed that the odds of overweight is lower when breakfast is consumed on five or more days per week $^{(7)}$.

\section{Fruit and vegetable consumption}

Fruit and vegetable consumption were assessed by the questions: 'How many days per week do you eat fruit?' and 'How many days per week do you eat vegetables?' Response values ranged from 0 to $7^{(22,23)}$. To calculate the percentage of adolescents meeting the guidelines for fruit and vegetable consumption, dichotomous variables were made for respectively daily $(7 \mathrm{~d} /$ week $)$ fruit and daily vegetable consumption. The Netherlands Nutrition Centre recommends to consume fruit and vegetables every day ${ }^{(24)}$.

\section{Physical activity}

Questions on physical activity were modified in the electronic questionnaire in school year 2010-2011. In the paper questionnaire, physical activity questions were only related to active transport to school and participation in sports in leisure time. However, in the electronic questionnaire, two questions on physical activity were added, resulting in four different topics related to physical activity: (i) participation in sport activities outside; (ii) participation in sport activities in a sports club; (iii) school gymnastics; and (iv) active transport to school (walking or cycling). A last question was added (based on those four different physical activities) to assess the 
percentage of children who meet the Dutch healthy exercise norm (NNGB) of being physically active for at least one hour per day ${ }^{(25)}$. Because this question was not included in the paper questionnaire, it was only possible to assess the threeyear trends in physical activity (2010-2011 to 2012-2013). The question used to assess how many children were physically active for more than one hour per day was: 'Think of last week. How many days of this week did you spent at least one hour on these activities? Thus walking or cycling from and to school, gymnastics at school, participation in sport activities in a sports club and/or sport activities outside a sports club (for example, playing soccer on the streets) ${ }^{,(26,27)}$. Response values ranged from 0 to 7 . To calculate the percentage of children meeting the guideline of at least one hour of physical activity each day, responses were dichotomized based on the number of days per week ( $<7$ or $7 \mathrm{~d} /$ week).

\section{Screen-time behaviour}

Total screen-time behaviour included computer use and watching TV. From school year 2006-2007 to school year 2009-2010, computer use was measured by using the question: 'How many days per week do you use the computer in your leisure time? Think of for example using internet at home, playing computer games, chatting'. To accommodate the societal changes in computer use, the question was modified in school year 2010-2011 to: 'How many days per week are you sitting behind a computer (internet, Game Boy, Nintendo) (not for school). Think of last week'. In school year 2011-2012 the question was modified again to: 'How many days per week are you sitting behind a computer (internet, Game Boy, Nintendo, video game console (not for school). Think of last week'. In school year 2012-2013 computer use was assessed by the question: 'How many days per week are you sitting behind a computer (laptop, tablet, video game console) (not for school). Think of last week'. Response values ranged from 0 to 7. To measure computer use in minutes per week the following question was used: 'How long do you on average use the computer in your leisure time?' Answer options were '<30 min/d', '30-60 min/d', '1-2 h/d', '3-4h/d' and ' $>4 \mathrm{~h} / \mathrm{d}$ '. Midpoints of the categorical variables were used $(15,45,90,160$ and $210 \mathrm{~min})$ to create a continuous variable of computer use in minutes per day. Subsequently, computer use in minutes per week was calculated by multiplying the number of days per week with the minutes per day. Watching TV was assessed by using the following questions: 'How many days per week do you watch TV (DVD) in your leisure time?' and 'How long do you on average watch TV (DVD) in your leisure time?' In a similar way to what is described above, the number of minutes of watching TV per week was calculated. Watching TV in minutes per week and computer use in minutes per week were summed and this sum was subsequently divided by seven to obtain screen-time behaviour in average minutes per day. It is advised to watch TV or play the computer for no longer than two hours per day on average ${ }^{(25)}$.
To calculate the percentage of adolescents adhering to this advice, a dichotomous variable was made with the cut-off points ' $<2 \mathrm{~h} / \mathrm{d}$ ' and ' $2 \mathrm{~h} / \mathrm{d}$ or more'.

\section{Educational level}

Students reported their educational level in the questionnaire. Four categories were made according to the Dutch secondary-school system from low to high: the practical pathway of pre-vocational education (PP VMBO), the theoretical pathway of pre-vocational education (TP VMBO), senior general secondary education (HAVO) and preuniversity education (VWO). For the present study, adolescents who were first grade students or who were enrolled in special education were excluded.

\section{Ethnicity}

Ethnicity was based on self-reported country of birth of both the student and his/her parents. Conforming with the Netherlands Central Bureau of Statistics, we defined a person to be of non-Dutch ethnic background when the person him/herself and/or at least one parent was foreignborn $^{(28)}$. For the present study, only the four main ethnic groups in the Netherlands were included, which are the Dutch, Surinamese, Turkish and Moroccan ethnic groups.

\section{Sociodemographic covariates}

Basic sociodemographic information, i.e. age, sex and postal code, which was used to determine the district of Amsterdam in which the student lived, was included in the questionnaires.

\section{Statistical analysis}

Data analysis was performed using the statistical software package IBM SPSS Statistics 20.0. A total of 36367 adolescents completed the questionnaires over seven years. Adolescents who were first grade students or were enrolled in special education ( $n$ 8330) were excluded, as were adolescents who did not belong to one of the four main ethnic groups ( $n$ 6342). We furthermore excluded participants with missing data on the covariates ( $n$ 2090) and on EBRB ( $n$ 361), resulting in a final study sample of 19244 individuals: 2351 in 2006-2007, 2547 in 2007-2008, 2185 in 2008-2009, 2580 in 2009-2010, 3230 in 2010-2011, 3331 in 2011-2012 and 3020 in 2012-2013.

After descriptive analyses to assess differences in sociodemographic variables across school years, logistic regression analyses were performed to assess seven-year time trends in regular breakfast consumption, daily vegetable consumption, daily fruit consumption, regular physical activity and positive screen-time behaviour. The EBRB were dichotomized so that a higher value indicated a more healthy behaviour. First, potential non-linearity of the association between time (as continuous independent variable) and all five healthy EBRB (as dichotomous dependent variables) was checked by adding a quadratic 
term to the regression equation. All associations between time and healthy EBRB were linear, except for daily vegetable consumption. Therefore the logistic regression analysis for daily vegetable consumption was performed with time as categorical instead of a continuous variable. School year 2006-2007 was used as the reference category. After linearity checks, logistic regression analyses were performed using a stepwise hierarchical adjustment approach. First, crude analyses were adjusted for age, sex and district of Amsterdam. Second, analyses were subsequently adjusted for educational level and ethnicity and interaction effects were tested. For this, two separate models were constructed: one to test for interaction between time and ethnicity (adjusted for age, sex, district of Amsterdam and educational level) and one to test for interaction between time and educational level (adjusted for age, sex, district of Amsterdam and ethnicity). If statistically significant effect modification was observed, trends in healthy EBRB were stratified according to educational level or ethnicity. Statistical significance levels were set at $P<0.05$.

\section{Results}

\section{Population characteristics}

Participants in the study were all second grade students with a mean age of 13.6 (sD 0.6) years (Table 1 ). Overall, $43.5 \%$ of the adolescents were of Dutch descent and $56.6 \%$ of Moroccan, Turkish or Surinamese descent. Just over $30 \%$ of the adolescents were enrolled in the practical pathway of pre-vocational education (PP VMBO) and about one-third in pre-university education (VWO). Although sociodemographic factors were significantly differently distributed across the school years $(P<0.05)$, the differences were relatively small.

\section{Healtby energy balance-related behaviours per school year}

Nearly $75 \%$ of the adolescents consumed breakfast for more than five days per week (Table 2). More adolescents met the guidelines for daily vegetable consumption (49.0\% consumed vegetables daily) than for daily fruit consumption ( $40.6 \%$ consumed fruit daily). On average $40.1 \%$ of the adolescents were watching TV or were behind the computer for less than two hours per day and approximately $16 \%$ were physically active for more than one hour per day.

\section{Time trends in bealtby energy balance-related bebaviours}

There was a significant linear increase over time of positive screen-time behaviour $(<2 \mathrm{~h} / \mathrm{d} ; \mathrm{OR}=1.04 ; 95 \% \mathrm{CI}$ $1.03,1.06)$ and a significant non-linear decrease over time of daily vegetable consumption (school year 2012-2013v. 2006-2007: OR=0.90; CI 0.80, 1.00; Table 3). Regular breakfast consumption, daily fruit consumption and regular physical activity were stable in the total population during the measured time period.

Table 1 Sociodemographic characteristics of 14-year-old adolescents participating in the Youth Health Monitor between school years 2006-2007 and 2012-2013, Amsterdam, the Netherlands

\begin{tabular}{|c|c|c|c|c|c|c|c|c|}
\hline & 2006-2007 & $2007-2008$ & 2008-2009 & 2009-2010 & 2010-2011 & 2011-2012 & 2012-2013 & Total \\
\hline Participants $(n)$ & 2351 & 2547 & 2185 & 2580 & 3230 & 3331 & 3020 & 19244 \\
\hline \multicolumn{9}{|l|}{ Age (years) } \\
\hline Mean & $13 \cdot 6$ & $13 \cdot 6$ & 13.5 & 13.5 & $13 \cdot 6$ & 13.5 & 13.7 & $13 \cdot 6$ \\
\hline SD & 0.7 & 0.7 & 0.6 & 0.6 & 0.7 & 0.6 & 0.7 & 0.6 \\
\hline \multicolumn{9}{|l|}{ Sex (\%) } \\
\hline Boys & $49 \cdot 6$ & $48 \cdot 7$ & $50 \cdot 8$ & $50 \cdot 3$ & $48 \cdot 8$ & $50 \cdot 1$ & 48.5 & $49 \cdot 5$ \\
\hline Girls & $50 \cdot 4$ & $51 \cdot 3$ & $49 \cdot 2$ & $49 \cdot 7$ & $51 \cdot 2$ & $49 \cdot 9$ & $51 \cdot 5$ & $50 \cdot 5$ \\
\hline \multicolumn{9}{|l|}{ District of Amsterdam (\%) } \\
\hline Centre & $5 \cdot 8$ & $6 \cdot 2$ & $7 \cdot 0$ & $6 \cdot 8$ & $6 \cdot 1$ & 6.5 & $7 \cdot 3$ & 6.5 \\
\hline East & $15 \cdot 3$ & $16 \cdot 0$ & $15 \cdot 9$ & $16 \cdot 8$ & $15 \cdot 8$ & $16 \cdot 9$ & $18 \cdot 0$ & $16 \cdot 4$ \\
\hline South-East & $8 \cdot 1$ & $10 \cdot 3$ & 8.4 & $10 \cdot 9$ & $9 \cdot 0$ & 7.9 & $8 \cdot 7$ & $9 \cdot 0$ \\
\hline South & $12 \cdot 0$ & 11.2 & $12 \cdot 6$ & 11.0 & 11.4 & 11.1 & $12 \cdot 7$ & 11.7 \\
\hline North & $11 \cdot 6$ & $11 \cdot 2$ & $9 \cdot 9$ & $11 \cdot 2$ & 14.9 & $15 \cdot 6$ & $15 \cdot 3$ & $13 \cdot 1$ \\
\hline West & $16 \cdot 6$ & $14 \cdot \overline{3}$ & $16 \cdot 5$ & $15 \cdot 6$ & $14 \cdot 1$ & 14.0 & $14 \cdot 0$ & 14.9 \\
\hline New-West & 30.5 & $30 \cdot 7$ & $29 \cdot 8$ & $27 \cdot 7$ & 28.9 & $27 \cdot 8$ & $24 \cdot 0$ & $28 \cdot 3$ \\
\hline \multicolumn{9}{|l|}{ Ethnicity (\%) } \\
\hline Dutch & $40 \cdot 1$ & $42 \cdot 9$ & 44.6 & 43.7 & 44.0 & $42 \cdot 8$ & $45 \cdot 8$ & 43.5 \\
\hline Moroccan & $27 \cdot 1$ & $24 \cdot 6$ & $25 \cdot 1$ & $25 \cdot 6$ & $25 \cdot 1$ & $27 \cdot 0$ & $25 \cdot 0$ & $25 \cdot 7$ \\
\hline Turkish & $16 \cdot 3$ & $14 \cdot 3$ & 14.9 & $12 \cdot 2$ & 13.7 & 14.7 & $13 \cdot 8$ & $14 \cdot 2$ \\
\hline Surinamese & $16 \cdot 5$ & $18 \cdot 2$ & 15.5 & 18.5 & $17 \cdot 2$ & $15 \cdot 5$ & $15 \cdot 5$ & $16 \cdot 6$ \\
\hline \multicolumn{9}{|l|}{ Educational level (\%) } \\
\hline Practical pre-vocational & 34.4 & $30 \cdot 9$ & $30 \cdot 3$ & 28.4 & 29.4 & $29 \cdot 8$ & 31.7 & $30 \cdot 6$ \\
\hline Theoretical pre-vocational & 23.4 & $23 \cdot 8$ & $23 \cdot 8$ & 23.8 & $23 \cdot 3$ & 23.7 & $20 \cdot 4$ & $23 \cdot 1$ \\
\hline Senior general secondary & $15 \cdot 0$ & 14.9 & $15 \cdot 5$ & $15 \cdot 8$ & $14 \cdot 7$ & $15 \cdot 1$ & $17 \cdot 2$ & $15 \cdot 5$ \\
\hline Pre-university & $27 \cdot 1$ & $30 \cdot 3$ & $30 \cdot 4$ & 31.9 & $32 \cdot 6$ & 31.5 & 30.7 & $30 \cdot 8$ \\
\hline
\end{tabular}


Table 2 Percentages of 14-year-old adolescents participating in the Youth Health Monitor with healthy energy balance-related behaviours between school years 2006-2007 and 2012-2013, Amsterdam, the Netherlands

\begin{tabular}{|c|c|c|c|c|c|c|c|c|}
\hline & $\begin{array}{c}2006- \\
2007\end{array}$ & $\begin{array}{c}2007- \\
2008\end{array}$ & $\begin{array}{c}2008- \\
2009\end{array}$ & $\begin{array}{c}2009- \\
2010\end{array}$ & $\begin{array}{c}2010- \\
2011\end{array}$ & $\begin{array}{c}2011- \\
2012\end{array}$ & $\begin{array}{c}2012- \\
2013\end{array}$ & Total \\
\hline Regular breakfast consumption ( $\geq 5 \mathrm{~d} /$ week) & 73.7 & $74 \cdot 1$ & $77 \cdot 2$ & 74.8 & 74.0 & 73.8 & $76 \cdot 8$ & 74.8 \\
\hline Daily vegetable consumption & 49.5 & $52 \cdot 9$ & 53.4 & 53.9 & $45 \cdot 6$ & 43.5 & 47.5 & $49 \cdot 0$ \\
\hline Daily fruit consumption & 41.5 & 41.8 & 41.4 & $39 \cdot 3$ & 40.5 & 39.2 & 40.9 & $40 \cdot 6$ \\
\hline Positive screen-time behaviour $(<2 \mathrm{~h} / \mathrm{d})$ & $36 \cdot 2$ & 38.7 & $40 \cdot 9$ & 38.6 & 38.6 & $42 \cdot 8$ & 43.8 & $40 \cdot 1$ \\
\hline Regular physical activity $(\geq 1 \mathrm{~h} / \mathrm{d})^{*}$ & - & - & - & - & $16 \cdot 9$ & $15 \cdot 4$ & $16 \cdot 0$ & $16 \cdot 1$ \\
\hline
\end{tabular}

${ }^{*}$ No data were available from school year 2006-2007 to school year 2009-2010.

Table 3 Seven-year time trends in healthy energy balance-related behaviours among 14-year-old adolescents participating in the Youth Health Monitor, Amsterdam, the Netherlands

\begin{tabular}{|c|c|c|c|c|}
\hline & OR, crude & $95 \% \mathrm{Cl}$ & OR, adjusted $\dagger$ & $95 \% \mathrm{Cl}$ \\
\hline $\begin{array}{l}\text { Regular breakfast consumption ( } \geq 5 \mathrm{~d} / \text { week) } \\
\text { Daily vegetable consumption } \ddagger\end{array}$ & 1.01 & $0.99,1.03$ & 1.01 & $1.00,1.03$ \\
\hline Year 2007-2008 & $1 \cdot 15^{\star}$ & $1.03,1.23$ & $1 \cdot 14^{*}$ & $1.02,1.28$ \\
\hline Year 2008-2009 & $1 \cdot 17^{\star}$ & $1.04,1.31$ & $1 \cdot 14^{\star}$ & $1.01,1.28$ \\
\hline Year 2009-2010 & $1 \cdot 20^{*}$ & $1.07,1.34$ & $1 \cdot 17^{\star}$ & $1.05,1.31$ \\
\hline Year 2010-2011 & $0.86^{*}$ & $0.77,0.95$ & $0.85^{\star}$ & $0.76,0.95$ \\
\hline Year 2011-2012 & $0.79^{*}$ & $0.71,0.87$ & $0.77^{*}$ & $0.69,0.86$ \\
\hline Year 2012-2013 & 0.92 & $0.83,1.03$ & $0.90^{*}$ & $0.80,1.00$ \\
\hline Daily fruit consumption & 0.99 & $0.98,1.00$ & 0.99 & $0.98,1.00$ \\
\hline Positive screen-time behaviour ( $<2 \mathrm{~h} / \mathrm{d})$ & $1.05^{\star}$ & $1.03,1.06$ & $1.04^{*}$ & $1.03,1.06$ \\
\hline Regular physical activity $(\geq 1 \mathrm{~h} / \mathrm{d})$ & 0.97 & $0.90,1.03$ & 0.96 & $0.90,1.03$ \\
\hline
\end{tabular}

${ }^{*} P<0.05$.

†Adjusted for sex, age and district of Amsterdam

$\ddagger$ Non-linear trend.

\section{Time trends in bealthy energy balance-related behaviours according to educational level}

Interaction terms for time and educational levels were statistically significant for daily fruit consumption $(P=0 \cdot 017)$ and positive screen-time behaviour $(P=0 \cdot 002)$ and not statistically significant for daily breakfast consumption $(P=0 \cdot 60)$, daily vegetable consumption $(P=0 \cdot 80)$ and regular physical activity $(P=0 \cdot 21)$. Daily consumption of fruit decreased significantly $(P=0.001)$ for students who were enrolled in practical prevocational education (lowest educational level) between school years 2006-2007 and 2012-2013, but no statistically significant time trends in daily fruit consumption were found for other educational levels $(P=0 \cdot 29-0 \cdot 49$; Fig. 1$)$. Positive screen-time behaviour increased significantly for adolescents enrolled in pre-vocational education (practical and theoretical; $P<0.001)$ and general secondary education $(P=0 \cdot 003)$ over the seven years (Fig. 2), while no time trend was observed for adolescents enrolled in pre-university education $(P=0.82)$. In each year, the highest percentage of adolescents who reported healthy EBRB was observed among students enrolled in pre-university education $(P<0 \cdot 001)$.

\section{Time trends in bealthy energy balance-related behaviours according to ethnicity}

Interaction terms for time and ethnicity were statistically significant for daily fruit consumption $(P=0.018)$, daily vegetable consumption $(P<0 \cdot 001)$ and positive screen-time behaviour $(P<0 \cdot 001)$. The interaction terms for time and ethnicity were not significant for daily breakfast consumption $(P=0.069)$ and regular physical activity $(P=0.45)$. Daily fruit consumption decreased significantly in adolescents of Surinamese origin $(P=0.006)$ and adolescents of Turkish origin $(P=0 \cdot 015)$ over the seven years, but was stable in adolescents of Dutch origin $(P=0.63)$ and adolescents of Moroccan origin ( $P=0.81$; Fig. 3 ). Changes over time in daily vegetable consumption are presented in Fig. 4. Daily consumption of vegetables was significantly lower in school year 2012-2013 compared with school year 2006-2007 in adolescents of Turkish origin $(P=0.005)$ and adolescents of Moroccan origin $(P=0.006)$ but not in adolescents of Dutch origin $(P=0.93)$ and adolescents of Surinamese origin $(P=0.22)$. Positive screen-time behaviour increased significantly for adolescents of Surinamese origin $(P<0 \cdot 001)$, adolescents of Turkish origin $(P<0.001)$ and adolescents of Moroccan origin $(P=0.003)$, but was stable for adolescents of Dutch origin $(P=0.61$; Fig. 5$)$. In each year, the highest percentage of adolescents who reported healthy EBRB was observed among adolescents of Dutch ethnic background $(P<0 \cdot 001)$.

\section{Discussion}

To our knowledge, the present study is the first large-scale study assessing time trends in healthy EBRB, including regular breakfast consumption, daily fruit and vegetable 


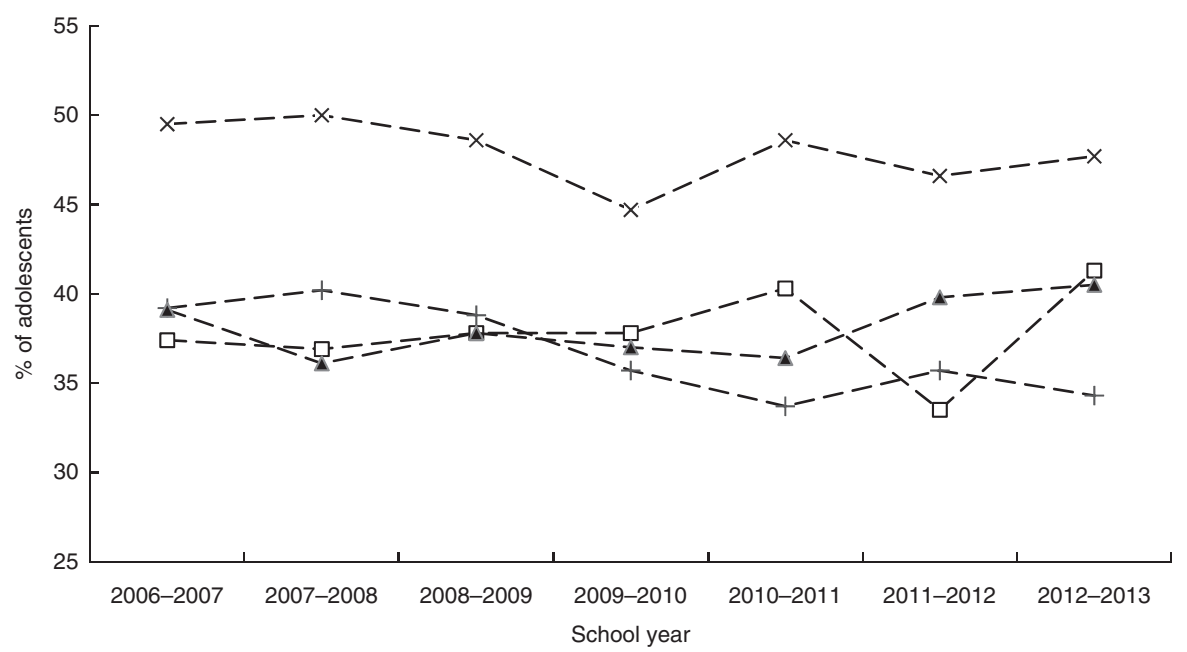

Fig. 1 Percentages of 14-year-old adolescents participating in the Youth Health Monitor meeting the guidelines for daily fruit consumption, stratified by educational level (+-+-+, practical pathway of pre-vocational education (PP VMBO); $\square-\square-\square$, theoretical pathway of pre-vocational education (TP VMBO); $\boldsymbol{\Delta}-\boldsymbol{\Delta}-\boldsymbol{\Delta}$, senior general secondary education (HAVO); $x-x-x$, pre-university education (VWO)), for school year 2006-2007 until school year 2012-2013, Amsterdam, the Netherlands. Odds ratios and 95\% confidence intervals adjusted for sex, age, district of Amsterdam and ethnicity, for school year 2012-2013 v. 2006-2007: PP VMBO $(\mathrm{OR}=0.96 ; 95 \% \mathrm{Cl} 0.93,0.98)$, TP VMBO (OR=1.01; $95 \% \mathrm{Cl} 0.98,1.04)$, HAVO (OR=1.02; $95 \% \mathrm{Cl} 0.98,1.06)$, VWO $(\mathrm{OR}=0.99 ; 95 \% \mathrm{Cl} 0.96,1.01)$

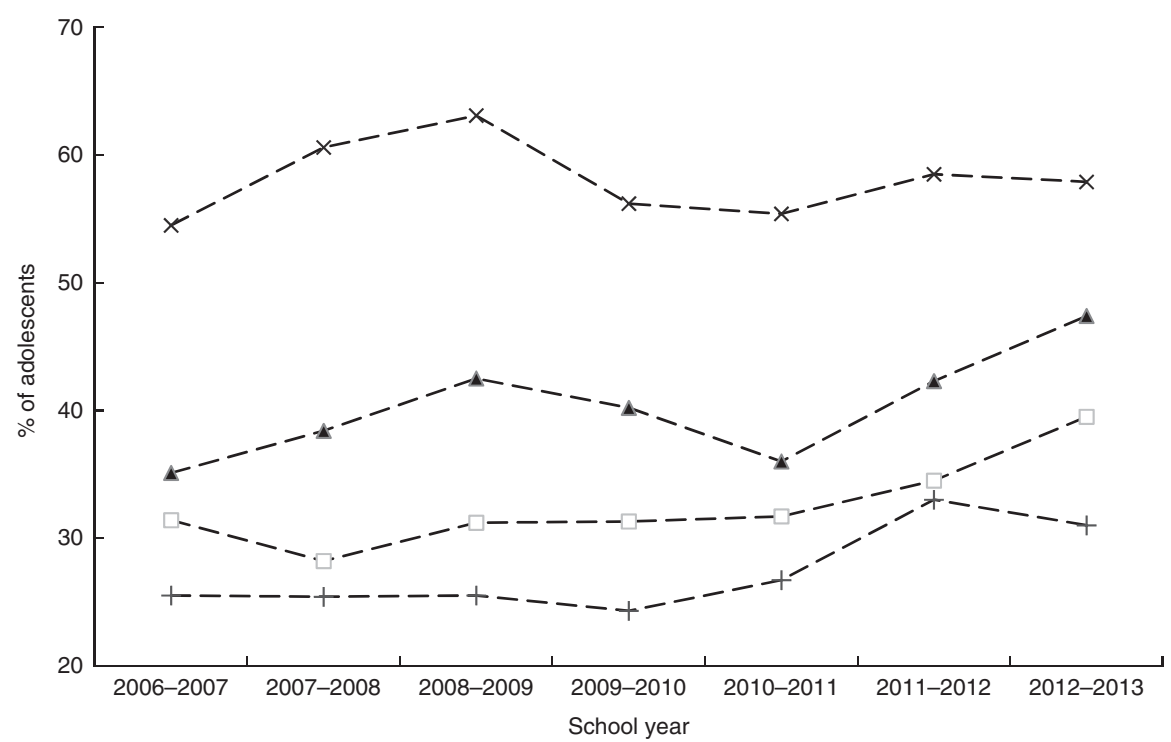

Fig. 2 Percentages of 14-year-old adolescents participating in the Youth Health Monitor meeting the advice for positive screen-time behaviour $(<2 \mathrm{~h} / \mathrm{d})$, stratified by educational level $(+-+-+$, practical pathway of pre-vocational education (PP VMBO); $\square-\square-\square$, theoretical pathway of pre-vocational education (TP VMBO); $\mathbf{\Delta}-\mathbf{\Delta}-\mathbf{A}$, senior general secondary education (HAVO); $x-x-x$, preuniversity education (VWO)), for school year 2006-2007 until school year 2012-2013, Amsterdam, the Netherlands. Odds ratios and $95 \%$ confidence intervals adjusted for sex, age, district of Amsterdam and ethnicity, for school year 2012-2013 v. 2006-2007: PP VMBO (OR = 1.06; $95 \% \mathrm{Cl} 1.03,1.10)$, TP VMBO (OR=1.06; $95 \% \mathrm{Cl} 1.03,1.10)$, HAVO (OR=1.06; $95 \% \mathrm{Cl} 1.02$, 1.10), VWO $(\mathrm{OR}=1.00 ; 95 \% \mathrm{Cl} 0.97,1.02)$

consumption, regular physical activity and positive screentime behaviour, according to educational level and ethnic background in adolescents living in an urban area. The results show that, among 14-year-old adolescents, positive screen-time behaviour increased significantly over seven years while daily vegetable consumption decreased from school year 2006-2007 to 2012-2013. Time trends in positive screen-time behaviour were significantly different across educational levels and ethnic backgrounds. For all educational levels and ethnic backgrounds an increase in positive screen-time behaviour was found except for the highest educational level and adolescents of Dutch origin. A decrease in daily fruit consumption was solely found among adolescents in the lowest educational level and among Surinamese and Turkish adolescents. Time trends in daily vegetable consumption were significantly different 


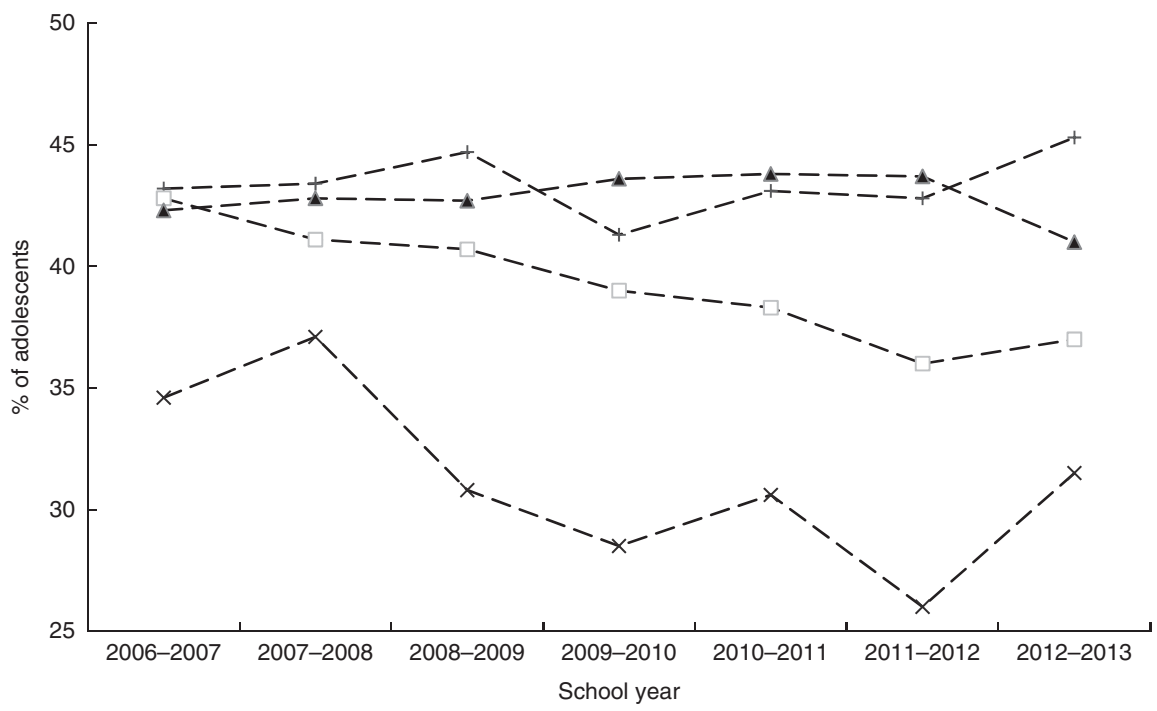

Fig. 3 Percentages of 14-year-old adolescents participating in the Youth Health Monitor meeting the guidelines for daily fruit consumption, stratified by ethnicity (+-+-+, Dutch; $\square-\square-\square$, Turkish; $\boldsymbol{\Delta}-\boldsymbol{\Delta}-\boldsymbol{\Delta}$, Moroccan; $x-x-x$, Surinamese), for school year 2006-2007 until school year 2012-2013, Amsterdam, the Netherlands. Odds ratios and $95 \%$ confidence intervals adjusted for sex, age, district of Amsterdam and educational level, for school year 2012-2013 v. 2006-2007: Dutch (OR =1.01; 95\% Cl 0.99, 1.03), Turkish (OR=0.95; $95 \% \mathrm{Cl} 0.92,0.99)$, Moroccan (OR=1.00; $95 \% \mathrm{Cl} 0.97,1.03)$, Surinamese $(\mathrm{OR}=0.95 ; 95 \% \mathrm{Cl} 0.91,0.99)$

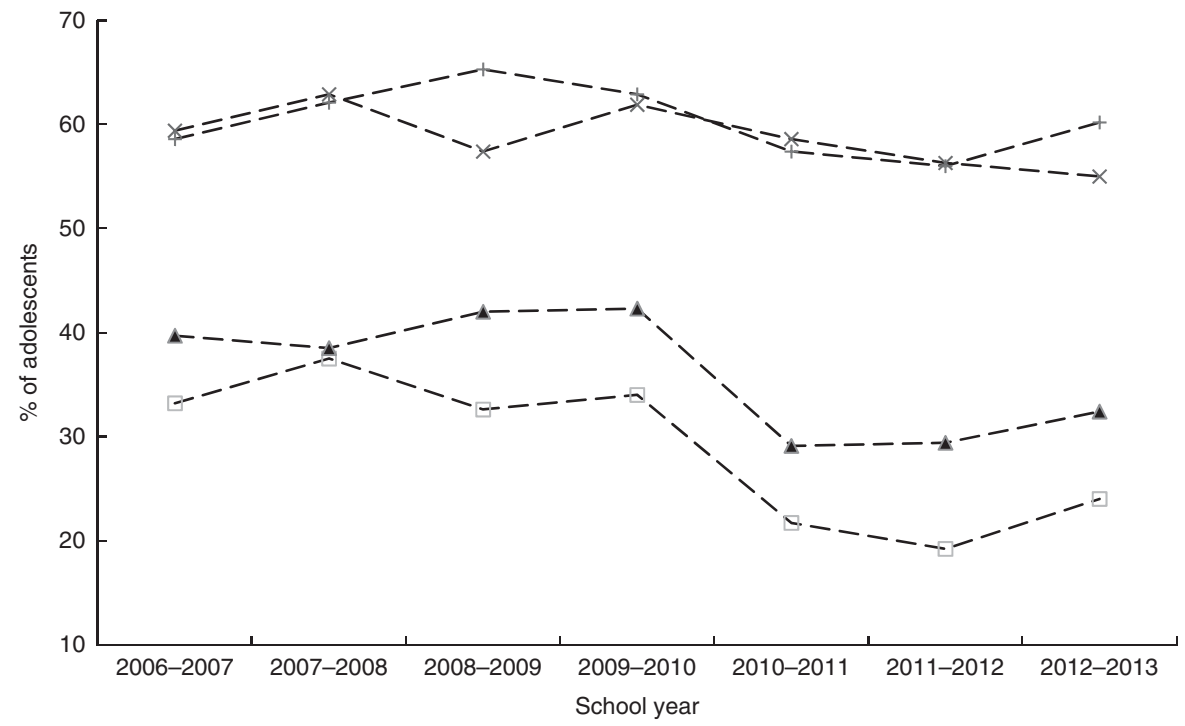

Fig. 4 Percentages of 14-year-old adolescents participating in the Youth Health Monitor meeting the guidelines for daily vegetable consumption, stratified by ethnicity (+-+-+, Dutch; $\square-\square-\square$, Turkish; $\boldsymbol{\Lambda}-\boldsymbol{\Delta}-\boldsymbol{\Delta}$, Moroccan; $\times-x-x$, Surinamese), for school year 2006-2007 until school year 2012-2013, Amsterdam, the Netherlands. Odds ratios and $95 \%$ confidence intervals adjusted for sex, age, district of Amsterdam and educational level, for school year 2012-2013 v. 2006-2007: Dutch (OR =1.02; 95\% Cl 0.86, 1.22),

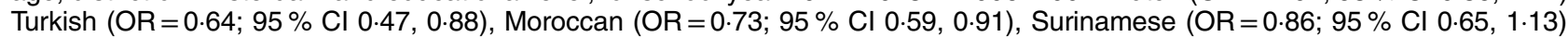

across ethnicity. Turkish and Moroccan adolescents consumed significantly less vegetables in school year 2012-2013 compared with school year 2006-2007.

\section{Screen-time behaviour}

The increase in positive screen-time behaviour between school years 2006-2007 and 2012-2013 is supported by a recent Norwegian study that found the proportion of adolescents engaging in screen-time behaviour for more than $2 \mathrm{~h} / \mathrm{d}$ decreased from $55 \%$ to $45 \%$ between 2001 and $2008^{(29)}$. In contrast, a German study found that screentime behaviour was stable between 2002 and 2010. They found a decrease in watching TV, however this was compensated for by an increase in non-gaming computer use $^{(30)}$. Further analyses of the screen-time variables in the present study (data not shown) revealed a decrease in both TV time and computer time. We cannot exclude the 


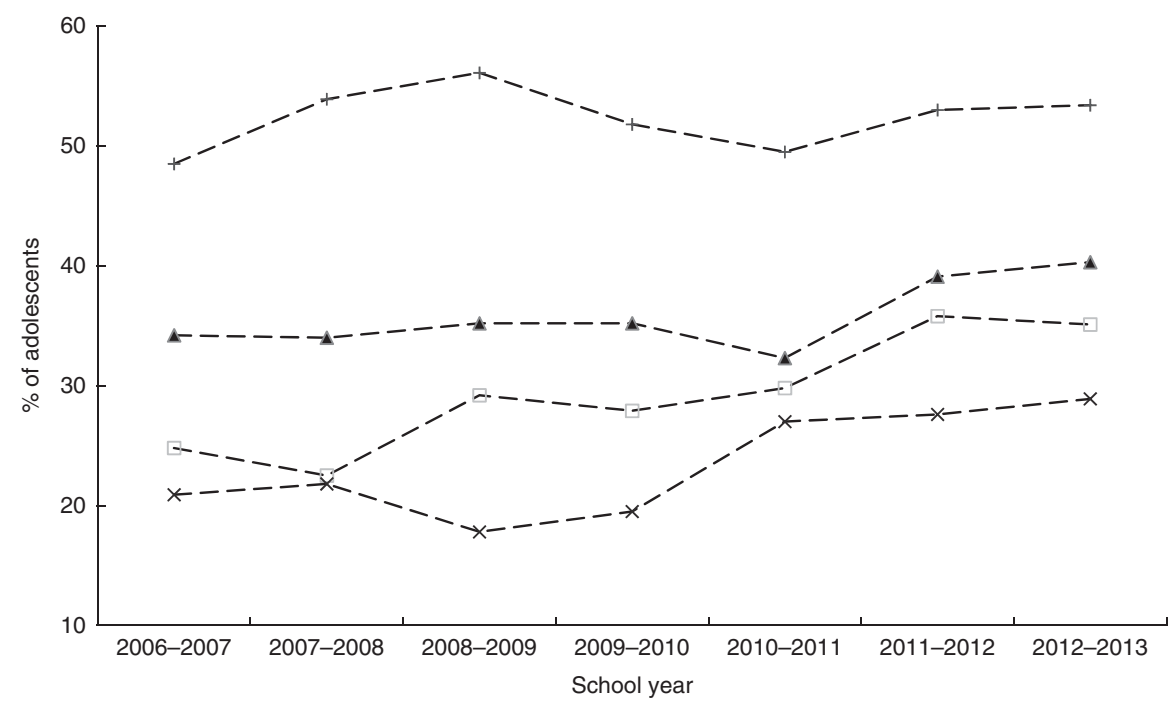

Fig. 5 Percentages of 14-year-old adolescents participating in the Youth Health Monitor meeting the advice for positive screen-time behaviour $(<2 \mathrm{~h} / \mathrm{d})$, stratified by ethnicity $(+-+-+$, Dutch; $\square-\square-\square$, Turkish; $\boldsymbol{\Delta}-\boldsymbol{\Delta}-\boldsymbol{\Delta}$, Moroccan; $\times-x-x$, Surinamese), for school year 2006-2007 until school year 2012-2013, Amsterdam, the Netherlands. Odds ratios and $95 \%$ confidence intervals adjusted for sex, age, district of Amsterdam and educational level, for school year 2012-2013 v. 2006-2007: Dutch (OR =1.00; 95\% Cl 0.98, 1.03), Turkish $(\mathrm{OR}=1.11 ; 95 \% \mathrm{Cl} 1.07,1.16)$, Moroccan $(\mathrm{OR}=1.05 ; 95 \% \mathrm{Cl} 1.02,1.08)$, Surinamese $(\mathrm{OR}=1.10 ; 95 \% \mathrm{Cl} 1.05,1.14)$

possibility that the decrease in TV time found in the present study was compensated for by the use of a smart phone. The National Youth Monitor in the Netherlands observed an increased use of (mobile) Internet among adolescents in the past decade, but also a decline in watching $\mathrm{TV}^{(31)}$. However, the smart phone is only fourth among the most-used mobile Internet devices (below laptop/MacBook, personal computer and video games console) ${ }^{(32)}$ and it is thus unclear to what extent smart phone use has influenced the total computer time of adolescents in our study.

Despite the increase in positive screen-time behaviour, there is much room for improvement considering the size of the changes over the seven years. The percentage of (non-pre-university education and non-Dutch) adolescents who watched TV or played the computer for no longer than two hours per day on average increased by approximately $10 \%$ in seven years and only $20-40 \%$ of these adolescents met the advice for positive screen-time behaviour. For adolescents enrolled in pre-university education or of Dutch origin, this percentage was about $60 \%$.

\section{Vegetable consumption}

The decrease in vegetable consumption in school year 2012-2013 compared with school year 2006-2007 is of concern, especially because adolescents are among the lowest vegetable consumers in the Dutch population ${ }^{(33)}$. The time trend for vegetable consumption was non-linear and the decline in vegetable consumption did not appear until school year 2010-2011. It might be possible that a modification of the question on vegetable consumption in the electronic questionnaire (partly) explains this decline.
In the paper questionnaire, used from school year 20062007 to school year 2009-2010, the following question was used to assess vegetable consumption: 'How many days per week do you eat vegetables? (e.g. tomato, broccoli, carrots, cabbage, mushrooms)'. The examples of different vegetables were not included in the electronic questionnaire, which may have caused an underestimation of the actual vegetable intake. Nevertheless, another study which used validated questionnaires, conducted among a large sample size of 11-year-old children in the Netherlands, also found a decrease in vegetable consumption between 2003 and $2009^{(34)}$. In addition, a decrease in vegetable consumption was found in the adult population in the Netherlands ${ }^{(13)}$.

The percentages of adolescents who met the guidelines for vegetable consumption were especially low for the adolescents of Turkish and Moroccan origin (respectively between 30 and $40 \%$ in school year 2006-2007 and 20 and $30 \%$ in 2012-2013). Even though these percentages were higher for adolescents of Dutch ethnic background and adolescents of Surinamese ethnic background (both between 55 and $65 \%$ ), stimulation of vegetable consumption remains important for all adolescents.

\section{Educational and ethnic differences}

In the current study, daily fruit consumption, regular breakfast consumption and regular physical activity were stable over time. Nevertheless, percentages of adolescents meeting guidelines for fruit consumption ( $40 \%$ ) and physical activity $(16 \%)$ were low, thus promotion of these EBRB remains an important topic for public health. This particularly holds for daily fruit consumption, which 
showed a significantly decreasing trend among adolescents with lower educational levels and adolescents of non-Dutch origin. In previous studies it was shown that lower socio-economic status associated with less favourable $\mathrm{EBRB}^{(35,36)}$. Indeed, in our study, the percentage of adolescents meeting the guidelines for healthy EBRB was the lowest for adolescents enrolled in pre-vocational education and the highest for adolescents enrolled in pre-university education. Trends in most EBRB (i.e. regular physical activity, daily vegetable consumption and regular breakfast consumption) were, however, similar across educational levels. Interestingly, an increase in positive screen-time behaviour (i.e. screen time $<2 \mathrm{~h} / \mathrm{d}$ ) was found among all educational levels except pre-university level. However, the fact that pre-university students reported a two times higher prevalence of healthy EBRB than prevocational students still emphasizes the need to focus prevention programmes targeting unhealthy behaviour on the lower educated adolescents.

The decreasing overweight prevalence among adolescents of Dutch ethnic background, but not among adolescents of non-Dutch ethnic background ${ }^{(5)}$, suggests that healthy EBRB could have increased among the adolescents of Dutch origin but not among the adolescents of Surinamese, Turkish or Moroccan origin. Indeed, trends in daily fruit and vegetable consumption were significantly different across ethnicities, but rather than an increase among students of Dutch ethnic background, we observed a decrease among the non-Dutch groups. In all ethnic groups, positive screen-time behaviour had increased over seven years' time, although as mentioned before, we had no data on smart phone use.

\section{Implications for health policy}

The generally lower percentages of healthy EBRB among lower educated and adolescents of non-Dutch ethnic background confirm the need to target these groups specifically. Educational interventions can be effective in promoting dietary intake, physical activity and positive screen-time behaviour ${ }^{(37-40)}$. Our results suggest that these interventions should be implemented especially in prevocational schools to reach the groups most at risk: on average $75 \%$ of non-Dutch adolescents are enrolled in pre-vocational education. An example of an intervention that promotes healthy dietary intake in secondary schools in the Netherlands is the 'Healthy School Canteen', which focuses on changing school nutrition policy and increasing the healthy product choices in school canteens. It was shown that children make healthier choices when the availability of healthy products is increased ${ }^{(41)}$.

\section{Strengths and limitations}

Some strengths and limitations should be considered while interpreting the results of the current study. A major strength is the high participation rate and the representativeness of the study sample. Each year, more than $90 \%$ of the schools took part in the project and sociodemographic characteristics of the participants were representative for all Amsterdam 14-year-olds ${ }^{(42,43)}$. Our study was therefore able to give a good representation of EBRB in adolescents in Amsterdam and, as such, a good indication of EBRB in a European urban city. However, extrapolating the results of the study to nonurban areas should proceed with caution ${ }^{(44)}$. A potential limitation of the study is the use of self-reported questionnaires, which could lead to socially desirable answering. To minimize this source of bias all students were informed about the confidentiality of their answers. Another possible limitation of the questionnaires might be the transition from the paper questionnaire to the electronic questionnaire in school year 2010-2011. The questions used to assess vegetable consumption and screen-time behaviour changed slightly in the electronic questionnaire and a significant change in both behaviours was found after use of the electronic questionnaire. However, the decrease in vegetable consumption and increase in positive screen-time behaviour were consistent with other studies ${ }^{(13,29,34)}$, although it remains possible that the latter is attributable to the lack of smart phone assessment. More importantly, Van de LooijJansen et al. previously observed that computer-based administration yields no other results than paper questionnaires ${ }^{(45)}$. The questions on EBRB were not validated for different educational levels and ethnic groups; therefore we cannot exclude the possibility of underestimation, particularly in the group of lower educated adolescents of non-Dutch ethnic background. However, potential underestimation is not likely to depend on school year and is therefore not likely to have affected our time trend analyses.

\section{Conclusion}

To our knowledge, the present study is the first large-scale study to examine time trends in healthy EBRB according to educational level and ethnicity among adolescents living in an urban area. Unfortunately we were not able to relate trends in EBRB to trends in overweight in this population. Nevertheless, our study provides important insight into current trends among groups most at risk, which will help to further develop and target health-promotion activities aimed at adolescents in an urban city. We found an increase in positive screen-time behaviour, but more research into the use of mobile phones is required. Overall, the discouragement of too much screen time and the promotion of other healthy behaviours, in particular daily fruit and vegetable consumption, remain important, particularly among adolescents enrolled in prevocational education and of non-Dutch ethnic background.

\section{Acknowledgements}

Acknowledgements: The authors gratefully acknowledge the assistance of Child Health Care employees in 
implementing the Youth Health Monitor. They would like to thank all schools and students for their participation. Financial support: This research received no specific grant from any funding agency in the public, commercial or notfor-profit sectors. Conflict of interest: None. Authorship: F.J.M. performed the statistical analyses, interpreted the data and drafted the manuscript. M.v.E. conceptualized the study and supervised the statistical analyses. C.L.v.V. coordinated the data collection and provided statistical advice, as did H.A.H.W. All authors contributed to critical revisions of the manuscript and have approved the final version. Ethics of buman subject participation: The Youth Health Monitor project is registered at the Dutch Data Protection Authority and uses a passive informed consent procedure.

\section{References}

1. Wang Y \& Lobstein T (2006) Worldwide trends in childhood overweight and obesity. Int J Pediatr Obes 1, 11-25.

2. Olds T, Maher C, Zumin S et al. (2011) Evidence that the prevalence of childhood overweight is plateauing: data from nine countries. Int J Pediatr Obes 6, 342-360.

3. Rokholm B, Baker JL \& Sørensen TIA (2010) The levelling off of the obesity epidemic since the year 1999 - a review of evidence and perspectives. Obes Rev 11, 835-846.

4. Schönbeck Y, Talma H, van Dommelen P et al. (2011) Increase in prevalence of overweight in Dutch children and adolescents: a comparison of nationwide growth studies in 1980, 1997 and 2009. PLoS One 6, 11.

5. De Wilde JA, Verkerk PH \& Middelkoop BJC (2014) Declining and stabilizing trends in prevalence of overweight and obesity in Dutch, Turkish, Moroccan and South Asian children 3-16 years of age between 1999 and 2011 in the Netherlands. Arch Dis Child 99, 46-51.

6. Rey-Lopez JP, Vicente-Rodríguez G, Biosca M et al. (2008) Sedentary behaviour and obesity development in children and adolescents. Nutr Metab Cardiovasc Dis 18, 242-251.

7. Croezen S, Visscher TLS, Ter Bogt NCW et al. (2009) Skipping breakfast, alcohol consumption and physical inactivity as risk factors for overweight and obesity in adolescents: results of the E-MOVO project. Eur J Clin Nutr 63, 405-412.

8. Ledoux TA, Hingle MD \& Baranowski T (2013) Relationship of fruit and vegetable intake with adiposity: a systematic review. Obes Rev 12, 143-150.

9. Ortega FB, Ruiz JR \& Castillo MJ (2013) Physical activity, physical fitness, and overweight in children and adolescents: evidence from epidemiologic studies. Endocrinol Nutr (Engl Ed) 60, 458-469.

10. Boulos R, Vikre Ek, Oppenheimer S et al. (2012) ObesiTV: how television is influencing the obesity epidemic. Physiol Behav 107, 146-153.

11. Kautiainen S, Koivusilta L, Lintonen T et al. (2005) Use of information and communication technology and prevalence of overweight and obesity among adolescents. Int J Obes (Lond) 29, 925-933.

12. Bassett R, Chapman GE \& Beagan BL (2008) Autonomy and control: the co-construction of adolescent food choice. Appetite 50, 325-332.

13. Hulshof FKAM, Brussaard JH, Kruizinga AG et al. (2003) Socio-economic status, dietary intake and $10 \mathrm{y}$ trends: The Dutch National Food Consumption Survey. Eur J Clin Nutr 57, 128-137.

14. Brugman E, Meulmeester JF, Spee-Van der Wekke A et al. (1998) Breakfast-skipping in children and young adolescents in The Netherlands. Eur J Public Health 8, 325-328.
15. O'Dea JA \& Caputi P (2001) Association between socioeconomic status, weight, age and sex, and the body image and weight control practices of 6- to 19-year-old children and adolescents. Health Educ Res 16, 521-532.

16. Stalsberg R \& Pedersen AV (2010) Effects of socio-economic status on the physical activity in adolescents: a systematic review of the evidence. Scand J Med Sci Sports 20, 368-383.

17. Mo F, Turner M, Krewski D et al. (2005) Physical inactivity and socio-economic status in Canadian adolescents. Int J Adolesc Med Health 17, 49-56.

18. Simons M, de Vet E, Brug J et al. (2014) Active and nonactive video gaming among Dutch adolescents: who plays and how much? J Sci Med Sport 17, 597-601.

19. Cornelisse-Vermaat JR \& Brink HM (2007) Ethnic differences in lifestyle and overweight in the Netherlands. Obesity (Silver Spring) 15, 483-483.

20. Brussaard JH, Van Erp-Baart MA, Brants HAM et al. (2001) Nutrition and health among migrants in The Netherlands. Public Health Nutr 4, 659-664.

21. Labree LJW, Van De Mheen H, Rutten FFH et al. (2011) Differences in overweight and obesity among children from migrant and native origin: a systematic review of the European literature. Obes Rev 12, e535-e547.

22. Martens MK (2005) Krachtvoer. The development, implementation and evaluation of an educational programme for 12-14-year-old students to promote healthy eating. $\mathrm{PhD}$ Thesis, Maastricht University.

23. De Nooijer J \& De Vries NK (2007) Monitoring health risk behaviour of Dutch adolescents and the development of health promoting policies and activities: the E-MOVO project. Health Promot Int 22, 5-10.

24. Voedingscentrum (2014) Schijf van Vijf. Eet Veel Groente, Fruit en Brood (The Disk of Five. Eat a Lot of Vegetables, Fruit and Bread). Den Haag: Netherlands Nutrition Centre; available at http://www.voedingscentrum.nl/nl/schijf-vanvijf/eet-veel-groente-fruit-en-brood.aspx

25. Kemper HGC, Ooijendijk WTM \& Stiggelbout M (2000) Consensus over de Nederlandse norm voor gezond bewegen (Concensus on the Dutch healthy exercise norm). Tijdschr Soc Gezondheidsz 78, 180-183.

26. Chinapaw MJ, Slootmaker SM, Schuit AJ et al. (2009) Reliability and validity of the Activity Questionnaire for Adults and Adolescents (AQuAA). BMC Med Res Methodol 9, 58 .

27. Wendel-Vos GC, Schuit AJ, Saris WH et al. (2003) Reproducibility and relative validity of the short questionnaire to assess health-enhancing physical activity. J Clin Epidemiol 56, 1163-1169.

28. Sanderse C \& Verweij A (2012) Etniciteit: Definitie en gegevens (Ethnicity, definition and data). In Volksgezondheid Toekomst Verkenning, Nationaal Kompas Volksgezondheid. Bilthoven: RIVM; available at http://www. nationaalkompas.nl/bevolking/etniciteit/wat-is-etniciteit/

29. Øverby NC, Klepp KI \& Bere E (2013) Changes in screen time activity in Norwegian children from 2001 to 2008: two cross sectional studies. BMC Public Health 13, 80.

30. Bucksch J, Inchley J, Zdenek H et al. (2014) Trends in television time, non-gaming PC use and moderate-to-vigorous physical activity among German adolescents 2002-2010. BMC Public Health 4, 351.

31. Centraal Bureau voor de Statistiek (2010) Landelijke jeugdmonitor: Rapportage $2^{\mathrm{e}}$ kwartaal 2010 (National Youth Monitor: Report 2nd Quarter 2010). Den Haag/Heerlen: CBS.

32. Rooij van AJ \& Schoenmakers TM (2013) Factsheet Monitor Internet en Jongeren. Het (mobiele) gebruik van sociale media en games door jongeren (Monitor Internet and Youth. The (mobile) Use of Social Media and Games by Youth). Rotterdam: Centrum for Behavioral Internet Science. 
33. Van Rossum TM, Fransen HP, Verkaik-Kloosterman J et al. (2011) The Dutch National Food Survey 2007-2010: Diet of Children and Adults Aged 7 to 69 Years. Bilthoven: National Institute for Public Health and the Environment.

34. Fischer C, Brug J, Tak NI et al. (2011) Differences in fruit and vegetable intake and their determinants among 11-yearold schoolchildren between 2003 and 2009. Int J Behav Nutr Phys Act 8, 141.

35. Horst K, Oenema A, Velde SJ et al. (2009) Sex, ethnic and school type differences in overweight and energy balancerelated behaviours among Dutch adolescents. Int J Pediatr Obes 4, 371-380.

36. Hanson MD \& Chen E (2007) Socio-economic status and health behaviours in adolescence: a review of the literature. J Behav Med 30, 263-285.

37. Van Cauwenberghe E, Maes L, Spittaels H et al. (2010) Effectiveness of school-based interventions in Europe to promote healthy nutrition in children and adolescents: systematic review of published and 'grey' literature. $\mathrm{Br} J$ Nutr 103, 781-797.

38. Jaime PC \& Lock K (2009) Do school based food and nutrition policies improve diet and reduce obesity? Prev Med 48, 45-53.

39. Van Grieken A, Ezendam NP, Paulis WD et al. (2012) Primary prevention of overweight in children and adolescents: a metaanalysis of the effectiveness of interventions aiming to decrease sedentary behaviour. Int JBehav Nutr Phys Act 9, 61.
40. Van Sluijs EM, McMinn AM \& Griffin SJ (2007) Effectiveness of interventions to promote physical activity in children and adolescents: systematic review of controlled trials. BMJ 335, 703 .

41. Kocken PL, Eeuwijk J, Van Kesteren N et al. (2012) Promoting the purchase of low-calorie foods from school vending machines: a cluster-randomized controlled study. J Sch Health 82, 115-122.

42. Ministerie van Onderwijs Cultuur en Wetenschap (2014) Monitor Trends in Beeld: Procentuele Verdeling in Het Derde Leerjaar (Monitor Trends: Percentual Division in the Third School Year). Den Haag: OCW; available at http:// www.trendsinbeeld.minocw.nl/grafieken/1_4.php

43. Centraal Bureau voor de Statistiek (2014) Regionale Kernciffers Nederland (Regional Key Figures the Netherlands). Den Haag/Heerlen: CBS; available at http://statline.cbs.nl/ StatWeb/publication/?DM=SLNL\&PA=70072NED\&D1=33$50,73 \& D 2=0,1213,103,126,229,247,251,586,610 \& D 3=5,13$, $1 \&$ $\mathrm{HDR}=\mathrm{T} \& \mathrm{STB}=\mathrm{G} 1, \mathrm{G} 2 \& \mathrm{VW}=\mathrm{T}$

44. Joens-Matre RR, Welk GJ, Calabro MA et al. (2008) Rural-urban differences in physical activity, physical fitness, and overweight prevalence of children. J Rural Health 24, 49-54.

45. Van de Looij-Jansen PM \& De Wilde EJ (2008) Comparison of web-based versus paper-and-pencil self-administered questionnaire: effects on health indicators in Dutch adolescents. Health Serv Res 43, 1708-1721. 